\title{
Perceived size and perceived distance in stereoscopic vision and an analysis of their causal relations*
}

\author{
TADASU OYAMA \\ Chiba University, Yayoicho, Chiba 280, Japan
}

\begin{abstract}
Effects of visual angle and convergence upon the perceived sizes and perceived distances of a familiar object (playing card) and a nonrepresentational object (blank white card) were investigated by means of a projector stereoscope with polarizing filters. The results obtained with six Ss indicated that size estimates increased nearly proportionally as the visual angle increased and decreased nearly linearly as the convergence increased. Distance estimates decreased nearly linearly as either the visual angle or the convergence increased. The ratio of the size estimate to the distance estimate for a given visual angle was almost constant irrespective of convergence. In this sense, the size-distance invariance hypothesis held. No clear effect of familiarity was found. Partial correlations were used to discriminate direct and indirect causal relationships between the stimulus variables and perceptual estimates. Both perceived size and perceived distance were found to be determined directly by the two stimulus variables, but to be mutually related only indirectly.
\end{abstract}

The usual relationship between perceived size and perceived distance can be described by the size-distance invariance hypothesis (SDIH), which states: "A retinal projection or visual angle of given size determines a unique ratio of apparent size to apparent distance" (Kilpatrick \& Ittelson, 1953; Epstein, Park, \& Casey, 1961). This relationship can be explained in at least three ways: (1) Apparent or perceived distance is determined by some stimulus cues, and apparent or perceived size is proportionally related to this perceived distance. (2) Perceived size is determined by stimulus cues, and perceived distance is proportionally related to this perceived size. (3) Both perceived size and perceived distance are determined by the same stimulus cues in the same way and, consequently, they are correlated with each other. A causal analysis developed by Simon (1954) and Blalock (1962) can be applied to determine which of these explanations is valid, if perceived size and perceived distance are simultaneously obtained under various conditions of stimulus cues.

Many studies indicated that visual angle as well as convergence affect both perceived size and perceived distance (Hermans, 1954; Lie, 1965; Oyama \& Iwawaki, 1972). Some investigators postulated that known or assumed size also affect perceived size and perceived distance (Ittelson, 1951a; Slack, 1956). However, in most previous studies, these variables were controlled separately, and their effects on perceived size and perceived distance were examined in different experimental series.

In the present study, effects of visual angle and convergence as well as effect of familiarity upon both

\footnotetext{
*The author wishes to thank Keiko Ichikawa for her assistance in this study and Professor W. C. Gogel for his critical reading of an early draft of this paper and his many valuable suggestions. A part of this study was reported at the 31st Convention of the Japanese Psychological Association, Tokyo, July 1967. Requests for reprints should be sent to Tadasu Oyama, Department of Psychology, Chiba University, Yayoicho, Chiba 280, Japan.
}

perceived size and perceived distance were simultaneously investigated in a stereoscopic apparatus in which stimulus cues can be controlled independently (Ogasawara, 1935; Oyama \& Sato, 1967; Lawson \& Gulick, 1970). The effect of familiarity was studied by comparing the results obtained with two kinds of stimulus objects, a playing card (familiar object) and a white card (nonrepresentational object), under every condition of stimulus cues. This approach permits the study of the combined as well as the individual effects of these three variables on the two dependent variables. To clarify individual effects of visual angle and convergence, accommodation was kept constant, though it was varied correspondingly to the variation of convergence in some previous studies (Leibowitz \& Moore, 1966; Wallach \& Floor, 1971). For the same reason, effects of retinal disparity were eliminated by using a completely dark background, while the effects were systematically studied in some other previous investigations (Oyama \& Sato, 1967; Lawson \& Gulick, 1970; Oyama \& Iwawaki, 1972). The present study examined the SDIH and causal relations in it in a situation in which visual angle, convergence, and familiarity were systematically varied and other variables were kept constant.

\section{METHOD}

\begin{abstract}
Apparatus
A stereoscopic apparatus was used in the present experiment. ${ }^{1}$ This consisted of a dark visual alley at one end of which was a funnel-shaped viewing hood and an observation window with a daylight screen at the other end. The distance between the observation window and the screen was $230 \mathrm{~cm}$. Two $5 \times 5 \mathrm{~cm}$ polarizing filters, with axes perpendicular to each other, were inserted into the right and left halves of the observation window. Two projectors, 1 and 2, positioned under the hood also contained polarizing filters, whose axes were oriented so that the image on the screen from Projector 1 could be seen only through the right half of the observation window and the image projected from Projector 2 could be seen only through the left half of the window. A pair of neutral density filters was also inserted into
\end{abstract}


the two halves of the observation window to keep the background completely dark by reducing extraneous illumination resulting from any incomplete polarization. The entire apparatus was located in a lightproof room.

\section{Stimulus Materials}

Pairs of positive colored photographic transparencies of a playing card (Queen of Spades) and a blank white card were stereoscopically presented by Projectors 1 and 2 on the daylight screen, with the remaining portion of the screen black. Each pair of transparencies in the two projectors was always identical, with the sizes of the pairs of playing cards or plain white cards varied in five steps. The heights of the projected images of the cards on the screen were $6.0,7.45,8.65,10.4$, and $12.3 \mathrm{~cm}$, respectively. The middle size is nearly the same as that of a standard playing card. These five heights subtend visual angles of $1 \mathrm{deg} 30 \mathrm{~min}$, $1 \mathrm{deg} 51 \mathrm{~min}, 2 \mathrm{deg} 9 \mathrm{~min}, 2 \mathrm{deg} 36 \mathrm{~min}$, and $3 \mathrm{deg} 3 \mathrm{~min}$, respectively. The luminance of the white part of the cards measured through the observation window was $0.5 \mathrm{~mL}$.

\section{Control of Convergence}

The projected image for the right eye was always located at a constant position on the screen, while that for the left eye could be displaced horizontally by varying the lateral displacement of Projector 2 by means of a gear system. When the two images are fused in binocular vision, the convergence angle,

$$
\alpha=57.3 \frac{\mathrm{a}-\mathrm{d}}{\mathrm{L}} \text { (in degrees), }
$$

where $a, d$, and $L$ are the interpupillary distance of the $S$, the lateral separation of the images on the screen for the right and left eyes, and the observation distance $(230 \mathrm{~cm})$, respectively.

Interpupillary distance varied among the Ss from 57 to $67 \mathrm{~mm}$. The middle of this range, $62 \mathrm{~mm}$, was used as the standard value of $a$ in the calculation of the convergence angles. The separation, $d$, between the two images was varied in six steps: $6,4,2,0,-4$, and $-8 \mathrm{~cm}$. The zero value indicates that the positions of the two images on the screen were identical, and the negative values mean that, on the screen, the images for the left eye were to the right of those for the right eye.

Substituting these six values of separation and the standard value of interpupillary distance in Eq. 1, we obtain six values of convergence angle, $\alpha: 3 \mathrm{~min}, 33 \mathrm{~min}, 1 \mathrm{deg} 3 \mathrm{~min}, 1 \mathrm{deg} 33 \mathrm{~min}$, $2 \mathrm{deg} 33 \mathrm{~min}$, and $3 \mathrm{deg} 33 \mathrm{~min}$. These values of $\alpha$ will vary in a range of $\pm 7.5 \mathrm{~min}$ if the individual rather than the standard interpupillary distance is used in Eq. 1. Thus, the smallest $\alpha$ for the $S$ of the smallest a was $-4.5 \mathrm{~min}$, indicating a slight divergence rather than convergence for this $S$ under this condition. Good fusion of the stereoscopic images was obtained by every $S$ under every condition.

\section{Subjects}

Six undergraduate students majoring in psychology served in the preliminary training and the main experiment. They all had normal visual acuities in their two eyes. The interpupillary distances of the Ss were 61,61 , and $67 \mathrm{~mm}$ for the three men and 57,58 , and $63 \mathrm{~mm}$ for the three women.

\section{Preliminary Training of Size and Distance Estimation}

Two practice sessions were given for the size estimation and two more sessions for distance estimation. These sessions occurred with usual binocular viewing conditions but without the stereoscopic apparatus. In each practice session for the size estimation, 19 white cards of the same shape as the playing cards, with sizes varying geometrically from $1.1 \times 0.7 \mathrm{~cm}$ to $68.8 \times 45.6 \mathrm{~cm}$ were presented $115 \mathrm{~cm}$ from the $\mathrm{S}$ in a lighted experimental room, and were shown four times in random order. The $\mathrm{S}$ was asked to estimate the height of each card in centimeters. After each estimation, the $\mathrm{E}$ told the $\mathrm{S}$ the correct physical size. In each practice session for the distance estimation, a pole, $125 \mathrm{~cm}$ tall, was presented four times in random order at 15 different positions in an open field (flat rooftop). The distance to the pole was varied geometrically between 29 and $3,680 \mathrm{~cm}$. The $S$ was told the correct physical distance after each estimation.

\section{Procedure in the Main Experiment}

In the main experiment, the stereoscopic apparatus described above was used. Each $S$ served in four sessions. In two sessions, the photographic transparencies of the playing card were used as the stimulus materials, while in the other two sessions, those of the white card were used. In each session, a total of 30 conditions, all combinations of five sizes and six convergence angles, were presented in random order. The $S$ sat in a chair and observed the stereoscopic stimulus through the observation window. After obtaining good stereoscopic fusion, the $\mathrm{S}$ was asked to estimate first the apparent size (height) of the stimulus and then its apparent distance from himself, with both judgments in centimeters. Every condition of the two stimulus series (the playing card and the white card series) was presented twice. Between trials, the $S$ looked at a bright white surface of $200 \mathrm{~mL}$, located below the observation window and illuminated by ceiling lights, so as to keep his eyes light-adapted.

\section{RESULTS AND DISCUSSION}

Two size estimates and two distance estimates from each $S$ in each condition were averaged. Despite the training sessions, the magnitudes of estimates differed considerably between Ss. These individual differences were considered to be due to differences in verbalization rather than in perception, and for this reason the following transformation was made on the obtained size and distance estimates of individual Ss.

First, the middle-size stimulus under the convergence angle of $1 \mathrm{deg} 33 \mathrm{~min}$ was regarded as the standard condition. This size was selected as a standard since it is nearly the same as that of the standard playing card and since its two stereoscopic images coincided on the screen. In other words, the viewing conditions for this size were very similar to those for a real playing card presented $230 \mathrm{~cm}$ from the $S$. In this standard condition, the relation between accommodation and convergence were in agreement, while in the other conditions, the accommodation to the stimulus was constant with the convergence varying systematically.

The average size estimates for the standard stimulus given by individual Ss ranged from 7.5 to $11.15 \mathrm{~cm}$ for the playing cards and from 8.25 to $11.0 \mathrm{~cm}$ for the white cards. The average distance estimates ranged from 140 to $620 \mathrm{~cm}$ for the playing card and from 147.5 to $775 \mathrm{~cm}$ for the white card. It will be noted that there was some tendency for the size and distance estimates to be slightly greater for the white card than for the playing card. But these tendencies were not statistically significant (at the 5\% level).

For the purpose of transformation, all individual averages of the size and distance estimates of the playing and the white cards were multiplied by factors of $8.65 / \mathrm{S}_{\mathrm{s}}$ and $230 / \mathrm{D}_{\mathrm{s}}$, respectively, where $\mathrm{S}_{\mathrm{s}}$ and $\mathrm{D}_{\mathrm{s}}$ represent the individual averages of size and distance estimates of the standard stimulus. Group averages were 


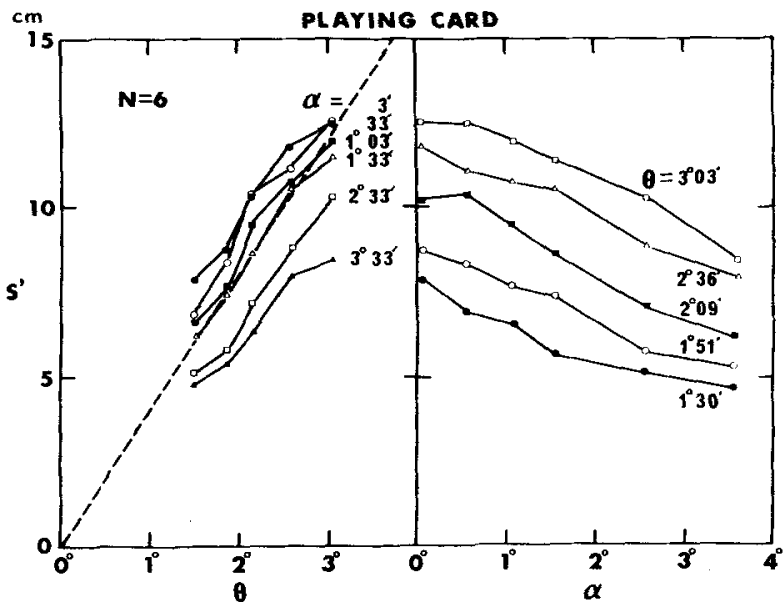

Fig. 1. Average size estimate $\left(S^{\prime}\right)$ as a function of visual angle $(\theta)$ and convergence $(\alpha)$ in the playing card series.

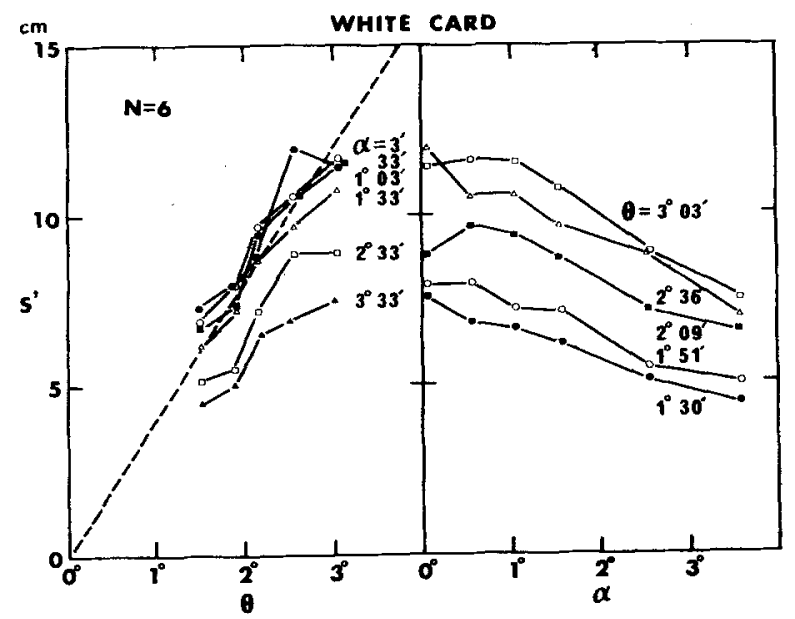

Fig. 2. Average size estimate $\left(S^{\prime}\right)$ as a function of visual angle $(\theta)$ and convergence $(\alpha)$ in the white card series.

obtained after this transformation was made on individual averages. This procedure served to equalize the contributions of the individual Ss to the group averages.

Figures 1 and 2 show the group averages of transformed size estimates, $S^{\prime}$, as functions of visual angle, $\theta$, and convergence angles, $\alpha$, in the playing card series and the white card series, respectively. The right and left halves of each figure show the same data obtained in the 30 different conditions ( 5 visual angles by 6 convergence angles). The dashed line in each figure is the physical size on the screen that subtends the visual angle shown on the abscissa. It will be noted that the solid line in each figure which indicates the transformed size score obtained for the convergence angle of $1 \mathrm{deg}$ 33 min lies fairly close to the dashed line. All of the solid lines in the left halves of these two figures indicate a clear tendency for size estimate, $S^{\prime}$, to increase nearly proportionally to visual angle, and all the lines in the right halves indicated that $S^{\prime}$ decreased nearly linearly as convergence angle increased. The latter tendency means that perceived size decreased as convergence increased for both the playing and white cards, even though visual angle was kept constant.

Figures 3 and 4 show the group averages of transformed distance scores, $D^{\prime}$, as functions of visual angle and convergence angle in the two stimulus series. It is clear that the distance estimates decreased as visual angle increased for both the playing and white cards, even though convergence was kept constant. It is also clear that distance estimates decreased nearly linearly as convergence angle increased for both kinds of cards with visual angle held constant.

Some investigators have attributed effects of visual angle on perceived size and perceived distance to the assumed size of familiar objects (Ittelson, 1951a, b; Epstein, 1961; Baird, 1963). According to this point of view, under reduced viewing conditions, familiar objects, e.g., playing cards, of physically (and retinally) different

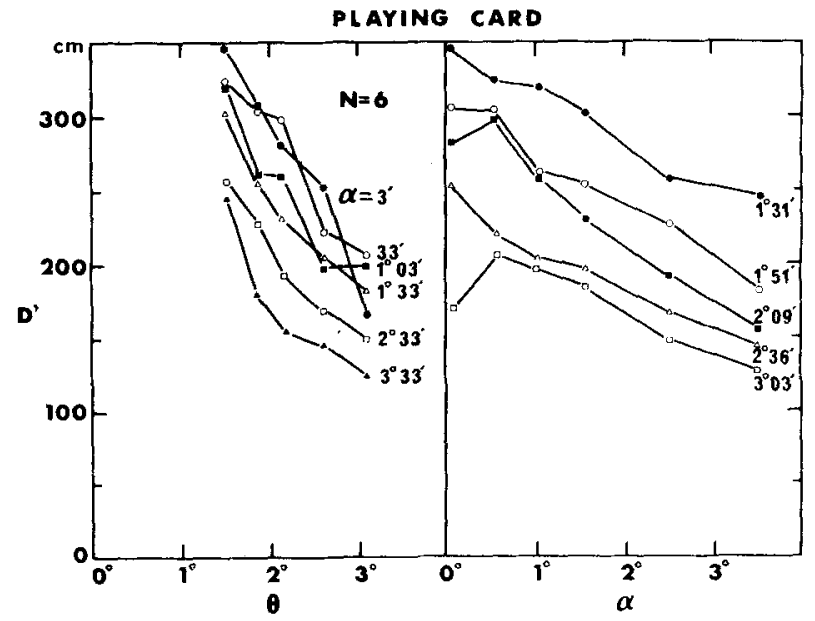

Fig. 3. Average distance estimate $\left(D^{\prime}\right)$ as a function of visual angle $(\theta)$ and convergence $(\alpha)$ in the playing card series.

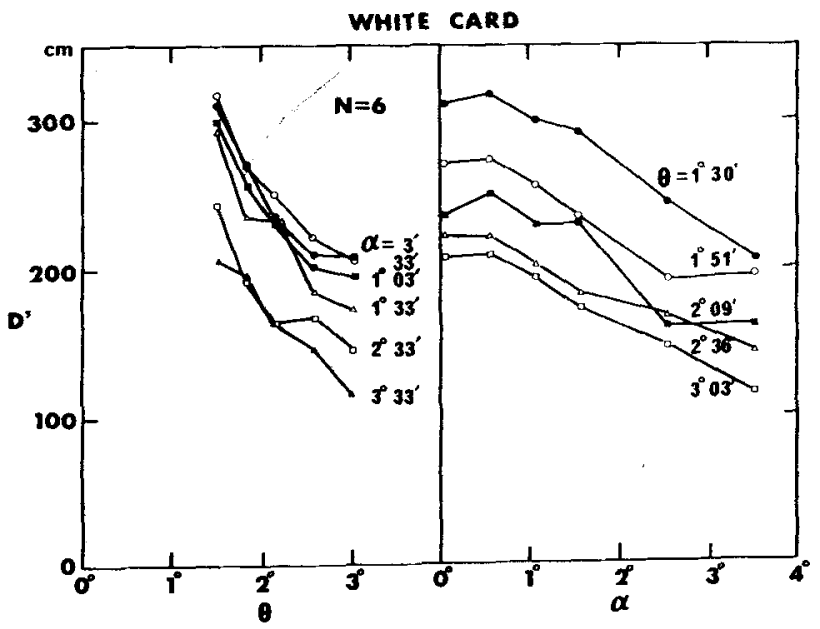

Fig. 4. Average distance estimate $\left(D^{\prime}\right)$ as a function of visual angle $(\theta)$ and convergence $(\alpha)$ in the white card series. 
sizes are expected to be perceived as having the same normal size but as being at different distances. The similarity of results between familiar and nonrepresentational objects in the present study is discordant with these expectations. This trend might be understood more adequately in relation to the effect of retinal size on perceived distance, which has been found even in situations in which only one object was presented at a time with similar objects of different retinal sizes presented successively (Gogel, 1969; Gogel \& Sturm, 1971). In these studies, the results obtained from the first presentation were largely different from the second or later presentations and these differences were considered to be caused by the relative size relation between successively presented objects. In the present study, differently sized images of the same kind of object were presented successively in the same session, and nearly the same effects of retinal size on perceived size and perceived distance were found for the familiar object and the nonrepresentational object. It follows that these results can be understood from the relative retinal size between successively presented images which have the same shape and the same pattern.

Although the convergence angle, which is inversely proportional to viewing distance, has often been considered to be a cue to distance, it is usually regarded as rather weak in its effect. Many experimental studies, in which convergence was systematically varied independently of accommodation and other depth cues, showed that perceived size as well as perceived distance gradually decreases as convergence angle increases (Swenson, 1932; Hermans, 1954; Heinemann, Tulving, \& Nachmias, 1959; Biersdorf, Ohwaki, \& Kozil, 1963; Oyama \& Iwawaki, 1972). The same tendency was confirmed in relation to the wallpaper phenomenon (Lie, 1965; Ono et al, 1971). However, the results of Gogel's (1961a, b, 1962a, b) studies showed that convergence was effective as a determiner of perceived size and perceived distance for only some of his Ss. In the present study, both the size and distance estimates systematically decreased as convergence increased in

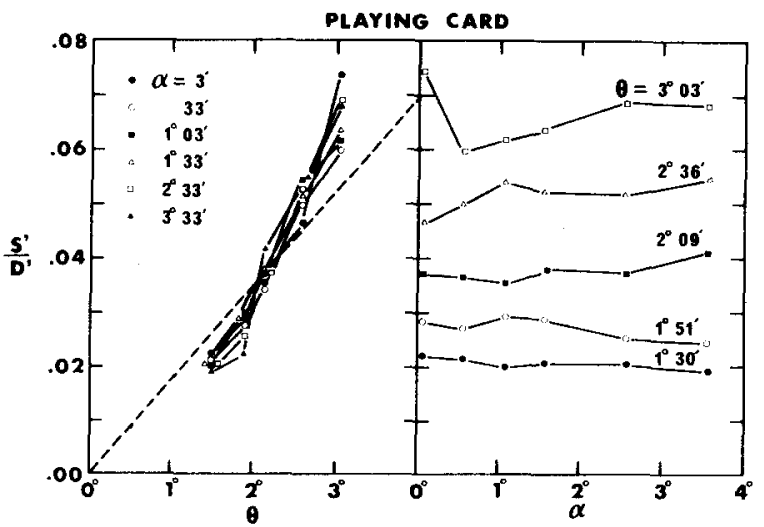

Fig. 5. Ratio of size estimate to distance estimate $\left(S^{\prime} / D^{\prime}\right)$ as a function of visual angle $(\theta)$ and convergence $(\alpha)$ in the playing card series.

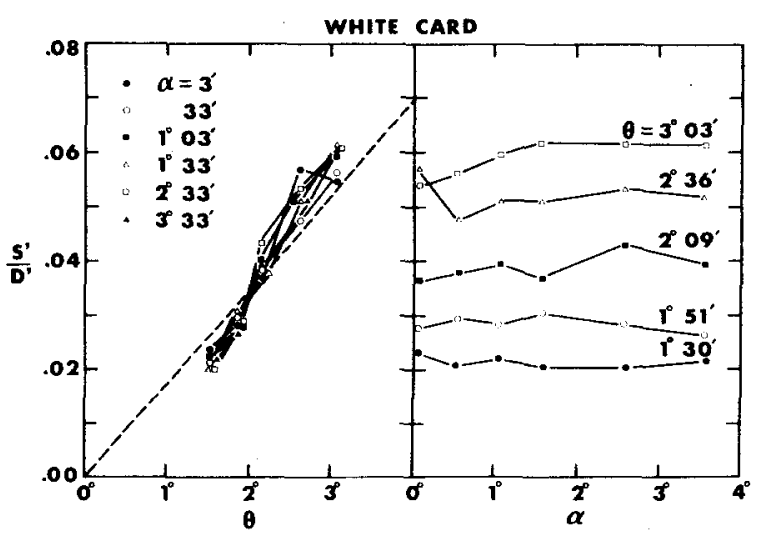

Fig. 6. Ratio of size estimate to distance estimate $\left(S^{\prime} / D^{\prime}\right)$ as a function of visual angle $(\theta)$ and convergence $(\alpha)$ in the white card series.

individual as well as in group data. This means that convergence was definitely one of the determiners of perceived size and perceived distance for all of the Ss of the present study, although its effects were rather small, as shown by small changes in perceived size and perceived distance caused by the large changes in convergence angle. The physical distances which give the smallest and largest convergence angles used in this study ( $3 \mathrm{~min}$ and $3 \mathrm{deg} 33 \mathrm{~min}$ ) for a $\mathrm{S}$ having the standard interpupillary distance $(62 \mathrm{~mm})$ were 71.0 and $1.0 \mathrm{~m}$, respectively. Oyama and Iwawaki (1972) reported that the logarithm of matched size decreased linearly as convergence angle increased. In the present study, the size estimate, not its logarithm, decreased linearly as convergence increased. However, the two equations do not show clear differences for data which have such a small range of variation in perceived size as in the present study.

To examine the SDIH, ratios of $S^{\prime} / D^{\prime}$ were obtained from the group averages of $S^{\prime}$ and $D^{\prime}$ for each condition. Figures 5 and 6 show the ratio of $\mathrm{S}^{\prime} / \mathrm{D}^{\prime}$ as functions of $\theta$ and $\alpha$. These figures show that the ratio of $S^{\prime} / D^{\prime}$ is nearly constant regardless of convergence angle, but that it increases as visual angle increases. The dashed lines in Figs. 5 and 6 indicate the physical ratios of size to distance for different values of visual angle. The obtained values $S^{\prime} / D^{\prime}$ show some systematic departures from the dashed lines, with these obtained ratios smaller than the physical ratios for small visual angles and greater than the physical ratios for large visual angles.

Foley (1968) and Gogel (1971) have suggested the following more general form of the SDIH:

$$
\mathrm{S}^{\prime} / \mathrm{D}^{\prime}=\mathrm{K} \theta^{\mathbf{n}} .
$$

To apply this power function to the present data, a $\log -\log$ plot was made for the values of $S^{\prime} / D^{\prime}$ averaged across five $O$ s in each stimulus series against $\theta$. Fairly good fits were observed, as shown by very high rs, 0.996 for the playing card series and 0.993 for the white card 
series. The values of $\mathrm{K}$ and $\mathrm{n}$ were 0.0112 and 1.56 for the playing card series and 0.0121 and 1.48 for the white card series, with these values very similar for the two kinds of cards.

\section{CAUSAL ANALYSIS}

As shown in the right portions of Figs. 5 and 6 , the ratio of size estimate to distance estimate, $S^{\prime} / D^{\prime}$, for a given visual angle, $\theta$, was nearly constant, irrespective of the convergence angle, $\alpha$, in the present experiment. This finding is in good agreement with SDIH. There are at least three possible explanations of this relationship, as indicated in the beginning of this paper. In Explanation 1, the effect of $\alpha$ on $S^{\prime}$ operates only through change of $\mathrm{D}^{\prime}$, and in Explanation 2, the effect of $\alpha$ on $D^{\prime}$ operates only through change of $S^{\prime}$. In this sense, if Explanation 1 or Explanation 2 is valid, either $\mathrm{D}^{\prime}$ or $\mathrm{S}^{\prime}$ has a direct relation with $\alpha$, but the remaining dependent variable $\left(S^{\prime}\right.$ or $\left.D^{\prime}\right)$ has only an indirect relation with $\alpha$. In Explanation 3, however, the effects of $\alpha$ on both $S^{\prime}$ and $D^{\prime}$ operate directly and independently and $S^{\prime}$ and $D^{\prime}$ are mutually related indirectly only through their common determinant, $\alpha$. Two more explanations are also possible. These are mixtures of Explanations 1 and 3 and of Explanations 2 and 3. In Explanation 4, the effect of $\alpha$ on $S^{\prime}$ operates not only directly but also indirectly through $\mathrm{D}^{\prime}$, which is determined by $\alpha$ only directly. In Explanation 5, the effect of $\alpha$ on $D^{\prime}$ operates directly and indirectly through $S^{\prime}$, which is determined by $\alpha$ only directly.

Mathematically, if we assume linear relations between these variables, the relations in Explanation 1 will be represented as follows:

$$
\begin{aligned}
& D^{\prime}=\mathrm{a} \alpha+\mathrm{u} \\
& \mathrm{S}^{\prime}=\mathrm{b} \mathrm{D}^{\prime}+\mathrm{v},
\end{aligned}
$$

where $\mathrm{a}$ and $\mathrm{b}$ are constants and $\mathrm{u}$ and $\mathrm{v}$ are random factors. From Eqs. 3 and 4, we can derive that

$$
r_{\alpha S}=r_{\alpha D} \times r_{S D}
$$

In this and the following equations, prime marks of $S^{\prime}$ and $D^{\prime}$ are omitted from suffixes for simplification. From Eq. 5, we can also derive that the partial correlation between $\alpha$ and $S^{\prime}$ with $D^{\prime}$ kept constant is zero,

$$
\mathrm{r}_{\alpha \mathrm{S} \cdot \mathrm{D}}=0,
$$

because the numerator of the partial correlation is defined as $r_{\alpha \mathbf{S}}-r_{\alpha \mathbf{D}} \times r_{\mathbf{S} D}$, which becomes zero according to Eq. 5. Similarly, in Explanation 2,

$$
\begin{aligned}
& S^{\prime}=a^{\prime} \alpha+u^{\prime} \\
& D^{\prime}=b^{\prime} S^{\prime}+v^{\prime},
\end{aligned}
$$

where $a^{\prime}$ and $b^{\prime}$ are constants and $u^{\prime}$ and $v^{\prime}$ are random factors. Hence,

$$
\mathrm{r}_{\alpha \mathbf{D}}=\mathrm{r}_{\alpha \mathbf{S}} \times \mathrm{r}_{\mathbf{S D}}
$$

and

$$
\mathrm{r}_{\alpha \mathrm{D} \cdot \mathrm{s}}=0 .
$$

The relations in Explanation 3 will be represented as follows:

$$
\begin{aligned}
& S^{\prime}=a^{\prime \prime} \alpha+u^{\prime \prime} \\
& D^{\prime}=b^{\prime \prime} \alpha+v^{\prime \prime},
\end{aligned}
$$

where $\mathrm{a}^{\prime \prime}$ and $\mathrm{b}^{\prime \prime}$ are constants and $\mathrm{u}^{\prime \prime}$ and $\mathrm{v}^{\prime \prime}$ are random variables. From Eqs. 11 and 12, we can derive that

$$
r_{S D}=r_{\alpha S} \times r_{\alpha D}
$$

and

$$
\mathrm{r}_{\mathrm{SD} \cdot \alpha}=0 .
$$

In Explanations 4 and 5, we cannot derive such simple relations and any partial correlation will not be zero.

The use of partial correlations for causal inference was proposed by Simon (1954), who showed more precise mathematical derivation of the above relations. A partial correlation is a net correlation between two variables when the influence of one or more additional variables have been eliminated. For instance, $r_{\alpha S} \cdot D$ indicates correlation between $\alpha$ and $S^{\prime}$ when the influence of $D^{\prime}$ has been eliminated. This partial correlation becomes zero, as indicated in Eq. 6, when the effect of $\alpha$ on $S^{\prime}$ operates only through change of $D^{\prime}$, whose influence has been eliminated in this correlation. It should also be noticed that by the use of partial correlation we can discriminate only between direct and indirect relations but cannot decide the direction of causality. Other scientific knowledge indicates the direction of causality. In the present study, it is clear that the causal arrows start from the experimentally controlled variables, $\alpha$ and $\theta$, not from the $\mathrm{Ss}$ ' responses, $\mathrm{S}^{\prime}$ and $\mathrm{D}^{\prime}$.

In the above discussion, we considered only one independent variable, $\alpha$, but actually we also used another independent variable, $\theta$, in the present study. Consequently, we have to treat four variables in our causal analysis, instead of three as in Simon's original method. Fortunately, Blalock (1962) developed a method to extend Simon's type of causal analysis to four-variable cases. According to Blalock, we have to compute not only first-order partial correlations, in each of which one variable is kept constant, but also second-order partial correlations, in each of which two variables are kept constant. Obtained patterns of partial correlations having nearly zero values will suggest causal relations among variables. 
Table 1

Simple and Partial Correlations Between Visual Angle $(\theta)$, Convergence $(\alpha)$, Group Averages of Size Estimate $\left(S^{\prime}\right)$, and Distance Estimate ( $\left.D^{\prime}\right)$ (Prime Marks are Omitted in Suffixes)

\begin{tabular}{llcr}
\hline & & Playing Card & White Card \\
\hline \multirow{4}{*}{ Simple } & $\mathrm{r}_{\theta \mathrm{S}}$ & $0.802^{* *}$ & $0.762^{* *}$ \\
Correlations & $\mathrm{r}_{\theta \mathrm{D}}$ & $-0.744^{* *}$ & $-0.705^{* *}$ \\
& $\mathrm{r}_{\alpha \mathrm{S}}$ & $-0.574^{* *}$ & $-0.592^{* *}$ \\
& $\mathrm{r}_{\alpha \mathrm{D}}$ & $-0.617^{* *}$ & $-0.651^{* *}$ \\
& $\mathrm{r}_{\mathrm{SD}}$ & -0.231 & -0.159 \\
& $\mathrm{r}_{\theta \mathrm{S}} \cdot \alpha$ & $0.979^{* *}$ & $0.945^{* *}$ \\
& $\mathrm{r}_{\theta \mathrm{S}} \cdot \mathrm{D}$ & $0.969^{* *}$ & $0.928^{* *}$ \\
& $\mathrm{r}_{\theta \mathrm{D}} \cdot \alpha$ & $-0.945^{* *}$ & $-0.928^{* *}$ \\
First-Order & $\mathrm{r}_{\theta \mathrm{D}} \cdot \mathrm{S}$ & $-0.961^{* *}$ & $-0.913^{* *}$ \\
Partial & $\mathrm{r}_{\alpha \mathrm{S}} \cdot \theta$ & $-0.960^{* *}$ & $-0.914^{* *}$ \\
Correlations & $\mathrm{r}_{\alpha \mathrm{S}} \cdot \mathrm{D}$ & $-0.935^{* *}$ & $-0.928^{* *}$ \\
& $\mathrm{r}_{\alpha \mathrm{D}} \cdot \theta$ & $-0.923^{* *}$ & $-0.917^{* *}$ \\
& $\mathrm{r}_{\alpha \mathrm{D}} \cdot \mathrm{S}$ & $-0.940^{* *}$ & $-0.936^{* *}$ \\
& $\mathrm{r}_{\mathrm{SD}} \cdot \theta$ & $0.916^{* *}$ & $0.823^{* *}$ \\
& $\mathrm{r}_{\mathrm{SD}} \cdot \alpha$ & $-0.908^{* *}$ & $-0.889^{* *}$ \\
& $\mathrm{r}_{\theta \mathrm{S}} \cdot \alpha \mathrm{D}$ & $0.890^{* *}$ & $0.708^{* *}$ \\
Second-Order & $\mathrm{r}_{\theta \mathrm{D}} \cdot \alpha \mathrm{S}$ & $-0.671^{* *}$ & $-0.593^{* *}$ \\
Partial & $\mathrm{r}_{\alpha \mathrm{S}} \cdot \theta \mathrm{D}$ & $-0.748^{* *}$ & $-0.700^{* *}$ \\
Correlations & $\mathrm{r}_{\alpha \mathrm{D}} \cdot \theta \mathrm{S}$ & -0.369 & $-0.713^{* *}$ \\
& $\mathrm{r}_{\mathrm{SD}} \cdot \theta \alpha$ & 0.290 & -0.086 \\
\hline
\end{tabular}

**Significant beyond the $1 \%$ level

Table 1 shows simple correlations and first- and second-order partial correlations based on group averages of size and distance estimates. Most of the obtained correlations were highly significant, except that the simple correlations and second-order partial correlations between $\mathrm{S}^{\prime}$ and $\mathrm{D}^{\prime}, \mathrm{r}_{\mathbf{S D}}$ and $\mathrm{r}_{\mathrm{SD}} \cdot \theta \alpha$, were much smaller than the significance level and that the second-order partial correlation between $\alpha$ and $\mathrm{D}^{\prime}, \mathrm{r}_{\alpha \mathrm{D}} \cdot \theta \mathrm{S}$, in the playing card series was slightly smaller than the significance level. These correlations were also computed for individual Ss in each experimental series. Most of the obtained values showed the same tendencies as the correlations based on the group averages. It should be noticed that five of $\operatorname{six} r_{\alpha D} \cdot \theta s$ in the playing card series were significant, whereas the value based on the group averages did not reach significance. It means that this second-order partial correlation can be regarded as practically significant. All of the second-order partial correlations between $\mathrm{S}^{\prime}$ and $\mathrm{D}^{\prime}, \mathrm{r}_{\mathrm{SD}} \cdot \theta \alpha$, in individual data were insignificant except for one positive significant value in the white card series.

The significantly positive first-order partial correlation between $\mathrm{S}^{\prime}$ and $\mathrm{D}^{\prime}$ with $\theta$ kept constant, $\mathrm{r}_{\mathrm{SD} \cdot \theta}$, means that perceived size and perceived distance of the objects having a constant visual angle are positively correlated with each other. This relation is concordant with the SDIH. On the other hand, the significantly negative first-order partial correlation between the same two variables with $\alpha$ kept constant, $\mathrm{r}_{\mathrm{SD}} \cdot \alpha$, means that perceived size and perceived distance of the objects of various physical sizes presented at a constant distance are negatively correlated with each other: The objects appear larger and nearer as the visual angle increases.
This latter relation corresponds to results obtained by Epstein and Landauer (1969) and Landauer and Epstein (1969) in some of their experiments. It is interesting that both positive and negative correlations were found between the same two dependent variables, $S^{\prime}$ and $D^{\prime}$, depending on the choice of independent variable to be kept constant. In the results of the present study, correlations between $S^{\prime}$ and $D^{\prime}$ were nearly zero when neither of two independent variables, $\theta$ and $\alpha$, was kept constant and when both independent variables were kept constant. The correlations became significant only when one of the independent variables was kept constant. These facts suggest that the correlation between $S^{\prime}$ and $D^{\prime}$ was not substantial but only spurious, as in Explanation 3, because $\mathrm{S}^{\prime}$ and $\mathrm{D}^{\prime}$ should always be correlated, even when independent variables are kept constant and $S^{\prime}$ and $D^{\prime}$ fluctuate only randomly, if they are directly connected as in Explanations 1 and 2. In contrast with such relations between $S^{\prime}$ and $D^{\prime}$, significant second-order correlations obtained between $\theta$ and $\mathrm{S}^{\prime}$, between $\theta$ and $\mathrm{D}^{\prime}$, between $\alpha$ and $\mathrm{S}^{\prime}$, and between $\alpha$ and $D^{\prime}$ indicate the existence of direct relations between these variables. The effects of $\theta$ and $\alpha$ operated directly on both $S^{\prime}$ and $D^{\prime}$.

From the results of the causal analysis by means of partial correlations, we can conclude that both the perceived size and perceived distance obtained in the present study were directly determined by two stimulus variables, visual angle and convergence, and that the observed relation between perceived size and perceived distance was not based on a direct causal relation between them but was only a spurious relation indirectly induced by their common stimulus determinants. This conclusion may be consistent with the view proposed by Epstein and Landauer (1969) and Landauer and Epstein (1969), who regarded the perceived size and perceived distance as independent consequences of the same stimulus variable, visual angle.

\section{REFERENCES}

Baird, J. C. Retinal and assumed size cues as determinants of size and distance perception. Journal of Experimental Psychology, $1963,66,155-162$.

Biersdorf, $\dot{W}$. R., Ohwaki, S., \& Kozil, D. J. The effect of instructions and oculomotor adjustments on apparent size. American Journal of Psychology, 1963, 76, 1-17.

Blalock, H. M. Four-variable causal models and partial correlations, American Journal of Sociology, 1962, 68, 182-194.

Epstein, W. The known-size-apparent-distance hypothesis. American Journal of Psychology, 1961, 74, 333-346.

Epstein, W., \& Landauer, A. A. Size and distance judgments under reduced conditions of viewing. Perception \& Psychophysics, 1969,6, 269-272.

Epstein, W., Park, J., \& Casey, A. The current status of the size-distance hypothesis. Psychological Bulletin, 1961, 58, 491-514.

Foley, J. M. Depth, size and distance in stereoscopic vision. Perception \& Psychophysics, 1968, 3, 265-274.

Gogel, W. C. Convergence as a cue to absolute distance. Journal of Psychology, 1961a, 52, 287-301.

Gogel, W. C. Convergence as a cue to perceived distance of object in a binocular configuration. Journal of Psychology, $1961 \mathrm{~b}, 52,303-315$.

Gogel, W. C. Convergence as a determiner of perceived aksolute size. Journal of Psychology, 1962a, 53, 91-104.

Gogel, W. C. The effect of convergence on perceived size and distance. Journal of Psychology, 1962b, 53, 475-489. 
Gogel, W. C. The sensing of retinal size. Vision Research, 1969, 9,1079-1094.

Gogel, w. C. The validity of the size-distance invariance hypothesis with cue reduction. Perception \& Psychophysics, $1971,9,92-94$.

Gogel, W. C., \& Sturm, R. D. Directional separation and the size cue to distance. Psychologische Forschung, 1971, 35, 57-80.

Heinemann, E. G.. Tulving, E., \& Nachmias, J. The effect of oculomotor adjustments on apparent size. American Journal of Psychology, 1959, 72, 32-45.

Hermans, T. G. The relationship of convergence and elevation changes to judgments of size. Journal of Experimental Psychology, 1954, 48, 204-208.

Ittelson, W. H. Size as a cue to distance: Static localization. American Journal of Psychology, 1951a, 64, 54-67.

Ittelson, W. H. The constancies in perceptual theory. Psychological Review, 1951b, 58, 285-294.

Kilpatrick, F. P., \& Ittelson, W. H. The size-distance invariance hypothesis. Psychological Review, 1953, 60, 223-231.

Landauer, A. A. \& Epstein, W. Does retinal size have a unique correlate in perceived size? Perception \& Psychophysics, 1969, $6,273-275$

Lawson, R. B., \& Gulick, W. L. Apparent size and distance in stereoscopic vision. In J. C. Baird (Ed.), Human space perception: Proceedings of the Dartmouth Conference. Psychonomic Monograph Supplements, 1970, 3, 193-200.

Leibowitz, H., \& Moore, D. Role of changes in accommodation and convergence in the perception of size. Journal of the Optical Society of America, 1966, 56, 1120-1123.

Lie, I. Convergence as a cue to perceived size and distance. Scandinavian Journal of Psychology, 1965, 6, 109-116.

Ogasawara, J. Perceived size in stereoscopic vision. In K. Hirose (Ed.), Masuda Hakushi Shaon Shinrigaku Ronbunshu. Tokyo: Iwanami, 1953. Pp, 19-27. (In Japanese)
Ono, H., Mitson, L., \& Seabrock, K. Change in convergence and retinal disparities as an explanation for the wallpaper phenomenon. Journal of Experimental Psychology, 1971, 91, $1-10$.

Oyama, T., \& Iwawaki, R. Role of convergence and binocular disparity in size constancy. Psychologische Forschung, 1972 , $35,117-130$.

Oyama, T., \& Sato, F. Perceived size-ratio in stereoscopic vision as a function of convergence, binocular disparity and luminance. Japanese Psychological Research, 1967, 9, 1-13.

Slack, C. W. Familiar size as a cue to size in the presence of conflicting cues. Journal of Experimental Psychology, 1956, $52,194-198$.

Simon, H. A. Spurious correlation: A causal interpretation. Journal of the American Statistical Association, 1954, 49, 467-479.

Swenson, H. A. The relative influence of accommodation and convergence in the judgment of distance. Journal of General Psychology, 1932, 7, 360-380.

Wallach, H., \& Floor, L. The use of size matching to demonstrate the effectiveness of accommodation and convergence as cues for distance. Perception \& Psychophysics, 1971, 10, 423-428.

\section{NOTE}

1. This apparatus was essentially the same as that used by Oyama and Iwawaki (1972), who presented a schematic drawing of the apparatus. However, Screen 2 and Projectors 3 and 4 in it were not used in the present experiment.

(R eceived for publication August 7, 1973; revision received March 14,1974.) 